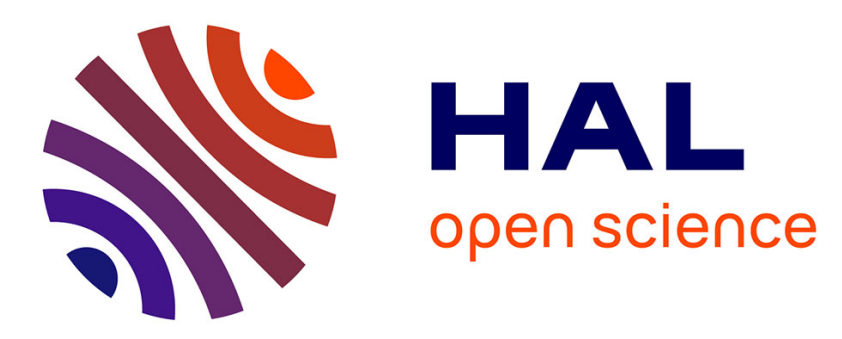

\title{
A redox reaction model for self-heating and aging prediction of $\mathrm{Al} / \mathrm{CuO}$ multilayers
}

Guillaume Lahiner, James Zapata, Jérémy Cure, Nicolas Richard, Mehdi

Djafari-Rouhani, Alain Estève, Carole Rossi

\section{To cite this version:}

Guillaume Lahiner, James Zapata, Jérémy Cure, Nicolas Richard, Mehdi Djafari-Rouhani, et al.. A redox reaction model for self-heating and aging prediction of $\mathrm{Al} / \mathrm{CuO}$ multilayers. Combustion Theory and Modelling, 2019, 23 (4), pp.700-715. 10.1080/13647830.2019.1584336 . hal-02061514

\section{HAL Id: hal-02061514 https://hal.science/hal-02061514}

Submitted on 8 Mar 2019

HAL is a multi-disciplinary open access archive for the deposit and dissemination of scientific research documents, whether they are published or not. The documents may come from teaching and research institutions in France or abroad, or from public or private research centers.
L'archive ouverte pluridisciplinaire HAL, est destinée au dépôt et à la diffusion de documents scientifiques de niveau recherche, publiés ou non, émanant des établissements d'enseignement et de recherche français ou étrangers, des laboratoires publics ou privés. 


\title{
A redox reaction model for self-heating and aging prediction of
}

\author{
$\mathrm{Al} / \mathrm{CuO}$ multilayers \\ G. Lahiner ${ }^{\mathrm{a}}$, J. Zappata ${ }^{\mathrm{a}}$, J. Cure ${ }^{\mathrm{a}}$, N. Richard ${ }^{\mathrm{b}}$, M. Djafari-Rouhani ${ }^{\mathrm{a}}$, A. \\ Estève $^{\mathrm{a}}$, C. Rossi ${ }^{\mathrm{a}}$ \\ ${ }^{a}$ LAAS-CNRS, University of Toulouse, 7 Avenue du colonel Roche, 31077 Toulouse, \\ France \\ ${ }^{b}$ CEA, DAM, DIF, Arpajon, France
}

\begin{abstract}
Sputter-deposited $\mathrm{Al} / \mathrm{CuO}$ multilayers capable of highly energetic reactions have been the subject of intense studies for tunable initiation and actuation. Designing high performance $\mathrm{Al} / \mathrm{CuO}$-based initiator devices definitively requires reliable prediction of their ignition and reaction kinetics including self-heating or aging as a function of heating rate and environmental conditions. The paper proposes a heterogeneous reaction model integrating an ensemble of basic mechanisms (oxygen diffusion, structural transformations, polymorphic phase changes) that have been collected from recent experimental investigations. The reaction model assumes that the rate of reaction is limited by the transport of oxygen across the growing layer of $\mathrm{Al}_{2} \mathrm{O}_{3}$ separating $\mathrm{Al}$ and $\mathrm{CuO}$. Importantly, we show that the model predicts reasonably all exotherms through a wide range of temperature (ambient $-1000^{\circ} \mathrm{C}$ ), all resulting from a pure diffusion process as experimentally observed for such $\mathrm{Al} / \mathrm{CuO}$ multilayers. The model shows how the temperature ramp affects the structure of the multilayer and especially the growth of alumina-based interfacial regions. It highlights the importance of the interfacial chemistry evolution such as the native mixture of $\mathrm{Al}_{\mathrm{x}} \mathrm{Cu}_{\mathrm{y}} \mathrm{O}_{\mathrm{z}}$ transformation into a thin amorphous alumina, and the polymorphic phase transformation of this latter. The first one occurring at $\sim 350{ }^{\circ} \mathrm{C}$ results in a loss of continuity of the interface leading to the accelerated redox
\end{abstract}


reaction whereas the second one occurring between 500 and $600{ }^{\circ} \mathrm{C}$ produces a denser barrier to oxygen diffusion leading to the stop of redox reaction. We finally use the model to simulate thermal annealing as usually performed in accelerated aging experiments. We theoretically observe and experimentally validate that a two weeks exposure of the multilayers at $200{ }^{\circ} \mathrm{C}$ starts degrading the multilayers thermal properties whereas when the temperature remains below $200{ }^{\circ} \mathrm{C}$, the material keeps its entire integrity.

Keywords: energetic materials, $\mathrm{Al} / \mathrm{CuO}$ multilayer, redox reactions; heterogeneous combustion

\section{Introduction}

Nanoscale sputter-deposited $\mathrm{Al} / \mathrm{CuO}$ thermite multilayers have attracted considerable attention in recent years due to their reactive properties, e.g. high volumetric energy density, significantly higher than most conventional secondary explosives, long shelf lives and compatibility with silicon integrated circuit processing. After being ignited locally by an external source of energy (electrostatic discharge, mechanical impact or local heating), they are capable to promptly release high amount of heat with emission of light, thus opening opportunities for on-chip ignition and micro actuation [1-4]. Two decades of research in $\mathrm{Al} / \mathrm{CuO}$ thermite multilayers have led to major progress in regulating either the fraction of material that reacts, or the time duration of the combustion, making it possible to envisage tunable initiation with further tailored energy and power outputs. However, despite huge experimental effort, the kinetics of both the initial exothermic reactions, leading to ignition, and low-temperature reactions, resulting in the material aging, remain elusive whereas it may greatly affect the sensitivity, overall exothermicity and ignition characteristics of the energetic multilayers. Although powderbased nanothermites are stable over long periods of time thanks to their protective alumina layer, sputter-deposited $\mathrm{Al} / \mathrm{CuO}$ multilayers are separated by a much less 
chemically controlled interfacial layer [5]. Therefore, it is reasonable to expect that both the ignition and aging kinetics are qualitatively and quantitatively different from those of the $\mathrm{Al} / \mathrm{CuO}$ mixed powders with identical stoichiometry, dimensional features, and composition. Along this line, a very recent and thorough experimental study [6] showed that: (i) the interfacial thickness in sputtered $\mathrm{Al} / \mathrm{CuO}$ multilayers is much larger than expected from usual surface native $\mathrm{Al}$ oxides, (ii) the release of gaseous $\mathrm{O}$ from the $\mathrm{CuO}$ well below reaction onset (i.e. at $\sim 200{ }^{\circ} \mathrm{C}$ ) initiates the $\mathrm{Al}$ oxidation process at the vicinity of native interfaces. (iii) the multiple subsequent redox reaction steps are the result of oxygen transport across the growing layer of $\mathrm{Al}_{2} \mathrm{O}_{3}$ separating $\mathrm{Al}$ and $\mathrm{CuO}$. These findings, together with close examination of previous published results [7], allow us to propose a redox reaction model of $\mathrm{Al} / \mathrm{CuO}$ sputter-deposited thin films integrating the structural and phase transformations, polymorphic phase changes occurring in $\mathrm{Al}_{2} \mathrm{O}_{3}$, in addition to thermally activated oxygen diffusion mechanisms coupled with heat equation. The final goal is to provide a new theoretical tool to simulate the calorimetric response of $\mathrm{Al} / \mathrm{CuO}$ sputter-deposited multilayers under slow heating rates and predict how temperature ramp affects the structure of the multilayer and especially the growth of interface $\left(\mathrm{Al}_{2} \mathrm{O}_{3}\right)$ making it possible, for the first time, to predict thermal aging.

Herein, we detail the model implementation, parametrization and validation based on a large set of experiments using Differential Scanning Calorimetry (DSC) performed isothermally in a broad range of temperatures (ambient to $1000{ }^{\circ} \mathrm{C}$ ). Its sensitivity to various material characteristics and heating conditions is explored. Then, the model is applied to simulate a two weeks accelerated thermal aging of $\mathrm{Al} / \mathrm{CuO}$ multilayers at 100 and $200{ }^{\circ} \mathrm{C}$ demonstrating its capability in predicting aging-induced materials performance modifications. 


\section{Materials and methods}

\subsection{Materials}

$\mathrm{Al} / \mathrm{CuO}$ multilayers are sputter deposited by DC (Direct Current) magnetron sputtering technique on a 4 inches $\mathrm{Si}(100)$ wafer. $\mathrm{Cu}$ and $\mathrm{Al}$ targets (8 and 3 inches sides and 1/4 inches thick) are used for the deposition of $\mathrm{CuO}$ and $\mathrm{Al}$ thin films. The base pressure of the chamber is less than $5 \times 10^{-7}$ mbar. $\mathrm{O}_{2}$ and Ar gases flow rates of 16 and $32 \mathrm{SCCM}$ (Standard Cubic Centimeters per Minute) respectively, are used for $\mathrm{CuO}$ deposition in reactive plasma at $600 \mathrm{~W}$ with a partial pressure of $8 \mathrm{mT}$ Torr, to obtain cupric oxide $(\mathrm{CuO})$. The partial pressure during $\mathrm{Al}$ deposition is maintained at 4 mTorr in Ar plasma at 800 $\mathrm{W}$. The $\mathrm{Al}$ and $\mathrm{Cu}$ target are localized in the same chamber. The sample stage moves at a speed of $244 \mathrm{~cm} / \mathrm{min}$ and $320 \mathrm{~cm} / \mathrm{min}$ respectively for the deposition of $\mathrm{CuO}$ and $\mathrm{Al}$. The sample is cooled during $600 \mathrm{~s}$ at the end of the deposition process.

Different sets of samples are prepared. All have 10 bilayers but the bilayer thickness $(w)$ and $\mathrm{Al}$ to $\mathrm{CuO}$ ratio ( $\varsigma: 1)$, ranges from 300 to $600 \mathrm{~nm}$ and 1:1 to 2:1, respectively. 1:1 $\mathrm{Al} / \mathrm{CuO}$ bilayer is a stoichiometric stack, where the thickness ratio provides sufficient moles of $\mathrm{O}$ in $\mathrm{CuO}$ to fully oxidize all the initial $\mathrm{Al}$ layer into $\mathrm{Al}_{2} \mathrm{O}_{3}$. Note that in a $1: 1$ $\mathrm{Al} / \mathrm{CuO}$ bilayer, the aluminum thickness is half the $\mathrm{CuO}$ thickness whereas in $\mathrm{s:l}$ $\mathrm{Al} / \mathrm{CuO}$, the $\mathrm{Al}$ thickness is $\frac{\varsigma}{2}$ of the $\mathrm{CuO}$ thickness, corresponding to a non-stoichiometric situation $(\varsigma \neq 1)$. For model parametrization, $10 \mathrm{Al} / \mathrm{CuO}$ bilayers in fuel rich condition (2:1) are prepared, each layer $(\mathrm{Al}$ and $\mathrm{CuO})$ being $200 \mathrm{~nm}$ in thickness. One advantage of this composition is that many experimentations on the reaction mechanisms are available in the literature $[6,8]$. 


\subsection{Thermal analysis}

The heat release during redox reaction of $\mathrm{Al} / \mathrm{CuO}$ multilayers is studied isothermally by DSC, using a NETZSCH DSC 404 F3 pegasus device. The device is equipped with a DSC- $C_{p}$ sensor type $S$ and a Platinum furnace in a temperature range from room temperature to $1000{ }^{\circ} \mathrm{C}$. Thermal analyses are performed under a constant heating rate in an Ar atmosphere. After the first heating cycle, the sample is cooled to room temperature, followed by a second heating cycle to correct the baseline. However, despite this second heating cycle, as the bulk heat capacity of the sample slightly drifts between the first and the second heating run, it is necessary to treat the experimental curves to obtain a suitable baseline. Note that this is a general difficulty encountered with DSC curves analysis due to the extended range of temperatures during the experiments combined with the complexity of $\mathrm{Al} / \mathrm{CuO}$ redox chemistry [6]. As the baseline is not linear, as observed by Umbrajkar et al. [9], we choose to build baselines following the isoconversional principle, assuming that the extent of reaction is conserved while following main exothermic events, at any heating rate.

\subsection{Theoretical approach}

We first use a model-free approach to evaluate the reaction kinetic parameters from the DSC curves. The best-known approach, if several measurements with different heating rates and/or different temperatures ranges are performed, is the method developed by Kissinger [10]. An effective reaction progress rate equation $\frac{d \alpha}{d t}=k_{o} \exp \left(-\frac{E_{a}}{R T}\right) \cdot f(\alpha)$ is presumed where $\alpha$ is the extent of reaction, and $E_{a}$ and $k_{o}$ are the activation energy and pre-factor associated with the transformation reaction, respectively. Assuming that DSC curve reaches a maximum at the peak transformation rate, the dependence of the peak temperature $\left(T_{p}\right)$ and the heating rate $(\beta=d T / d t)$ can be found by setting to zero the 
derivatives of the rate equation with respect to time. In the case of first-order reaction, i.e. $f(\alpha)=(1-\alpha)$, the resulting expression gives the so-called Kissinger equation:

$$
\ln \left(\frac{\beta}{T_{P}^{2}}\right)=\ln \left(\frac{k_{o} R}{E_{a}}\right)-\frac{E_{a}}{R T_{P}}
$$

with $R$, the ideal gas constant. Eq. 1 predicts that the plot $\ln \left(\frac{\beta}{T_{P}^{2}}\right)$ against $\frac{1}{R T_{P}}$ is a straight line with a $-E_{a}$ slope. However, despite the intensive application of Kissinger's method in interpreting DSC data [9,11-13], significant inaccuracies in the determination of $E_{a}$ may arise from the inherent methodological approximation. First, the physical meaning of the apparent kinetic parameters is not always clear: the concept of reaction progress should be limited to independent reactions occurring successively after each other, within specific temperature ranges, which is not the case in our system where elementary physical mechanisms interact with each other and occur concurrently at all temperatures, according to their specific kinetics. Also, thermal analysis data is fitted to an assumed $f(\alpha)$ function that can be chosen from a wide list of different functions that depend on the originating mechanisms [14], and using a "trial-and-error" procedure. Often for practical reasons, only first-order functions are considered which cannot interpret complex redox reaction and multiple phase transformation mechanisms, which may interfere within a single DSC peak. That is why we also developed an alternative method for the derivation of activation energies which is based on the setting up of a Fick diffusion equation implemented in the Deal \& Grove formulation [15], coupled with a thermal equation. Recently, this coupled approach enabled us to propose a combustion model that was inaugurated to perform flame velocity prediction in $\mathrm{Al} / \mathrm{CuO}$ multilayers, assuming a simple and reduced set of mechanisms [7]. We propose here to adapt it 
simulate heterogeneous redox reaction. Overall, considering 3 layers $i, j, k$ (see Figure 1), the model is based on four main equations:

- Material structural modification such as $\mathrm{CuO}$ densification and polymorphic phase change (amorphous to $\gamma-\mathrm{Al}_{2} \mathrm{O}_{3}$ transition) where an old structure is transformed into a new one at a given velocity. Until the transformation is complete, the variation of thicknesses is expressed as:

$$
d w_{j} / d t=v_{0 j} e^{-E_{j} / R T}
$$

where $w_{j}$ is the thickness of the considered $j$ phase (initially set to zero), $v_{0 j}$ and $E_{j}$ are respectively the velocity pre-exponent and activation energy relative to the phase transformation.

- Material chemical modification such as $\mathrm{CuO}$ reduction leading to oxygen release, where the associated reaction progress is given as:

$$
\frac{d \alpha_{i}}{d t}=A_{i} e^{-E_{i} / R T} f_{i}\left(\alpha_{i}\right)
$$

Where $\alpha_{i}$ is the extent of reaction (initially set to 0 , and equal to 1 when the reaction is complete), $A_{i}$ and $E_{i}$ are the pre-exponent and activation energy relative to the chemical modification of the material $i$. The progress function $f_{i}\left(\alpha_{i}\right)$ relates to the reaction type (diffusion, reaction, crystallization ...) [14].

- Mass transport equation in the flux $(\varnothing)$ approximation. Note that we only consider oxygen diffusion in our model:

$$
\varnothing=\frac{D_{j}\left(C_{i / j}-C_{j / k}\right)}{w_{j}}
$$


where $D_{j}$ is the oxygen diffusivity in the material $j$, the variables $C_{i / j,} C_{j / k} \ldots$ are the oxygen concentrations at interfaces between materials $i$ and $j, j$ and $k . w_{i}, w_{i}, w_{k}, \ldots$ correspond to the thicknesses of materials $i, j, k$ (see Figure 1). The oxygen diffusivity is expressed as:

$$
D_{j}=D_{o j} e^{-E_{j} / R T}
$$

For each layer, the pre-exponent $D_{o j}$ and activation energy $E_{j}$ are either taken from the literature relative to $\mathrm{Al} / \mathrm{CuO}$ nanopowder or calibrated on thermal analysis performed on our sputter-deposited 2:1 Al/CuO stacks. Parametrization issues are detailed in Results section 3.2.

- Thermal equation: $\quad P=\frac{d H(t)}{d t}-n S \phi \times Q$

$P$ is the differential external power (in W) as measured in DSC experiments. The total enthalpy $H\left(\right.$ in $\mathrm{J} / \mathrm{m}^{3}$ ) is expressed as: $H(t)=H_{a}+\sum_{T_{i}>T_{a}} M_{i} h_{i} \theta\left(T(t)-T_{i}\right.$ )

With, $H_{a}$, the total enthalpy of the bilayer at ambient temperature $\left(T_{a}\right)$ and $h_{i}$ the molar enthalpy corresponding to various phase transitions $i$ (such as Al melting) occurring at $T_{i}$ and $M_{i}$ the number of moles involved in the phase transition. $\theta$ is the Heaviside step function: $\theta=0$ for $T<T_{i}$, and $\theta=1$ for $T>T_{i}$.

The term $\phi \times \mathrm{Q}$ represents the heat released by the redox reaction at the Al/oxidizer interface $(i+k \rightarrow j$ in Figure 1). Note that $\mathrm{Q}$ is the heat of formation of the aluminium oxide in $\mathrm{J} / \mathrm{mol}$, is the oxygen flux across one bilayer in $\mathrm{mol} / \mathrm{m}^{3} / \mathrm{s}, n$ represents the number of bilayers in the film and $S$ its surface.

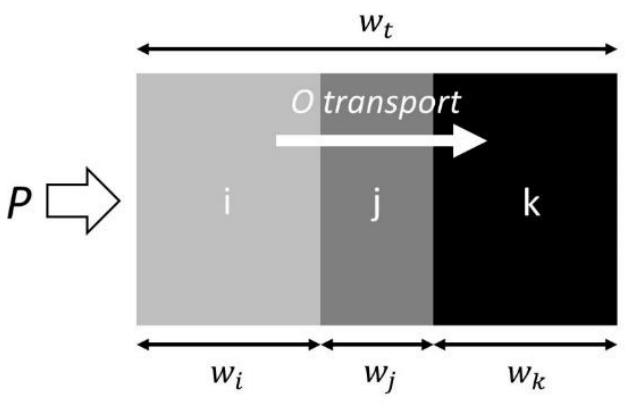


Figure 1. Schematic of one bilayer system submitted to a power density $P$. End to end repetition of this elementary bilayer unit constitutes a multilayer system.

\section{Results \& Discussion}

\subsection{Thermal analysis}

Figure 2 shows the DSC curves of 2:1 Al/CuO multilayers $(w=400 \mathrm{~nm})$ stacks collected at 5, 10, 20 and $40{ }^{\circ} \mathrm{C} / \mathrm{min}$. In each curve, we observe three main and reproducible exothermic events. A first broad exothermal event is observed between 350 and $540{ }^{\circ} \mathrm{C}$

(匹) followed by a strong exothermal peak at $540-670{ }^{\circ} \mathrm{C}(\bullet)$. A last exotherm at high temperature is detected between 670 and $900{ }^{\circ} \mathrm{C}(\boldsymbol{\Delta})$. Between $200-350{ }^{\circ} \mathrm{C}$, the copper oxide releases oxygen atoms that diffuse across the interfacial layers to oxidize the neighboring aluminum and form amorphous alumina $\left(\operatorname{am~} \mathrm{Al}_{2} \mathrm{O}_{3}\right)$. Because $\operatorname{am~}_{2} \mathrm{Al}_{2} \mathrm{O}_{3}$ density is substantially higher than that of naturally grown interface (mixture of $\mathrm{Al}, \mathrm{O}$ and $\mathrm{Cu}$ ), the structure of the interface is mechanically degraded at $\sim 350{ }^{\circ} \mathrm{C}$ (damaged $\mathrm{Al}_{2} \mathrm{O}_{3}$ ) leading to the accelerated redox reaction [5]. The resulting increase in am $\mathrm{Al}_{2} \mathrm{O}_{3}$ layer thickness provides a barrier to the oxygen diffusion that slows down $\mathrm{Al}$ oxidation, thus reducing the heat release corresponding to the drop of the first exotherm in the DSC trace $(\boldsymbol{\square})$. The second exothermal peak $(\bullet)$ corresponds to the main reaction stopped by a polymorphic phase change $\left(a m \mathrm{Al}_{2} \mathrm{O}_{3} \rightarrow \gamma-\mathrm{Al}_{2} \mathrm{O}_{3}\right)$. Then $\mathrm{Al}$ oxidation continues through the $\gamma-\mathrm{Al}_{2} \mathrm{O}_{3}$ before and after the aluminum melting. At $500{ }^{\circ} \mathrm{C}$, the XRD spectrum (Supplementary file Figure S1) presents a clear increase and welldefined $\mathrm{Cu}_{2} \mathrm{O}$ peaks with a small detection of a broad $\mathrm{Cu}(200)$ peak around $50.8^{\circ}$. But, $\mathrm{Al}_{2} \mathrm{O}_{3}$ phase is not yet detected, as it is still in its amorphous phase. Formation of $\gamma-\mathrm{Al}_{2} \mathrm{O}_{3}$ clearly occurs between 500 and $700{ }^{\circ} \mathrm{C}$ as it is detected at $700{ }^{\circ} \mathrm{C}$. At $700{ }^{\circ} \mathrm{C}$ (end of 
strong exothermal peak), traces of $\mathrm{CuAl}_{2}$ alloys are also detected by $\mathrm{XRD}$ as expected as the sample is $\mathrm{Al}$ rich.

Based on the Kissinger method described in the Theoretical approach subsection, the plots of $\ln \left(\beta / T_{p}^{2}\right)$ vs. 1000/ $T_{p}$ at each $T_{p}$ are shown in the Supplementary file Figure S2. The slopes of the straight lines corresponding to each group of data points correspond to activation energies $(155,206$ and $290 \mathrm{~kJ} / \mathrm{mol})$ related to exothermic peak 1 (घ), peak $2(\bullet)$ and peak $3(\boldsymbol{\Delta})$, respectively.

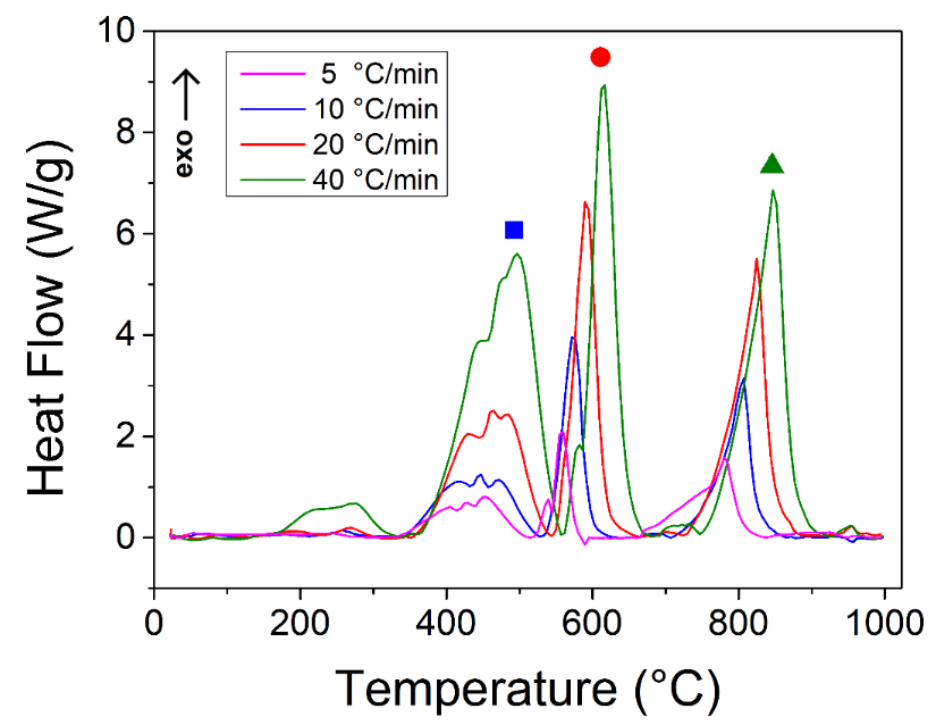

Figure 2. Experimental DSC curves of ten $2: 1 \mathrm{Al} / \mathrm{CuO}$ bilayers $(w=400 \mathrm{~nm})$ collected at different heating rates. Symbols are used to identify the exothermic peaks. Curves represent one experimental set repeated twice, to ensure that trends are well-captured. 


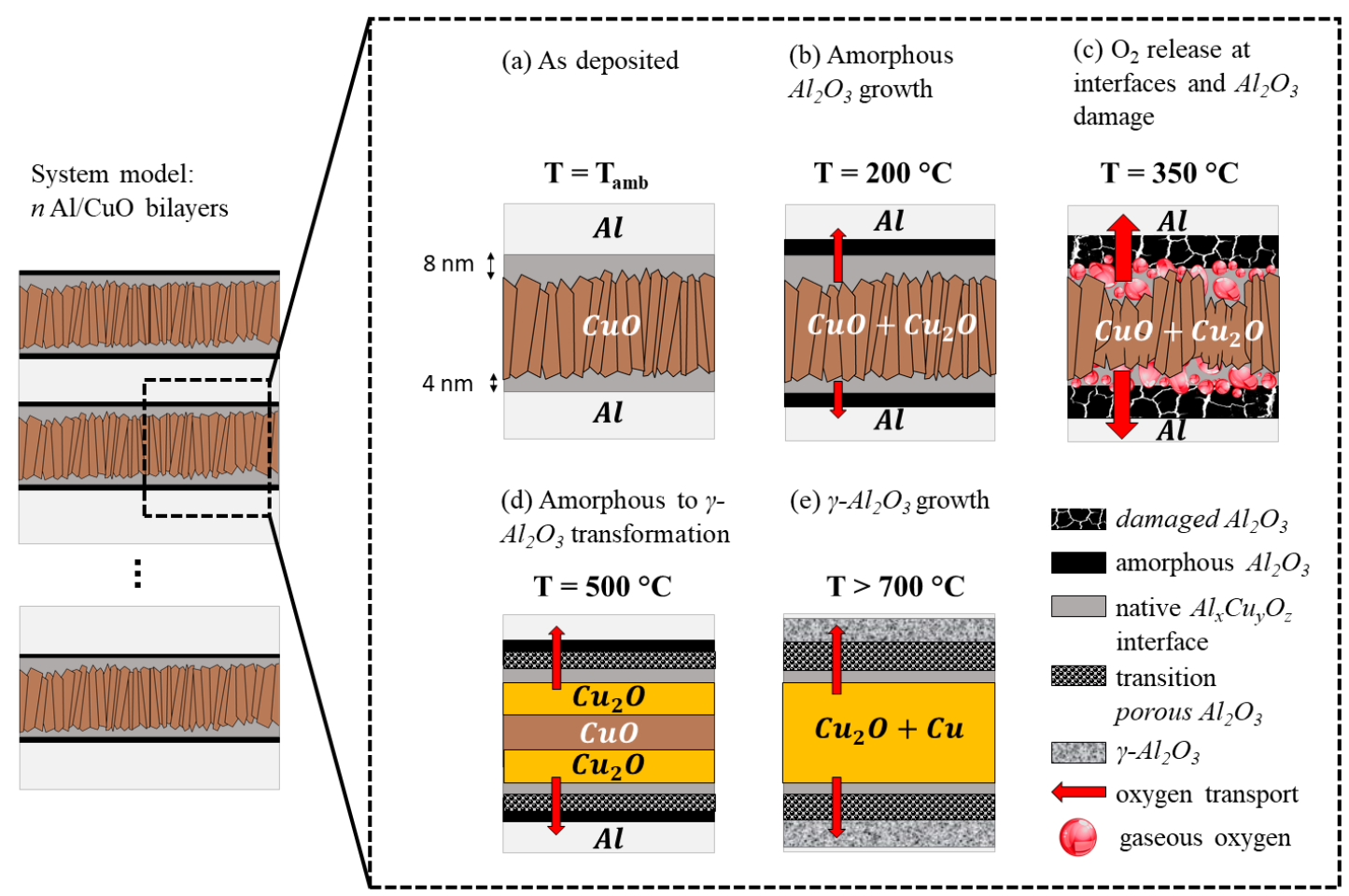

Figure 3. Schematics of the mechanisms proposed for describing the $\mathrm{Al}+\mathrm{CuO}$ redox reaction in sputter-deposited stacks under slow heating rate from ambient to $700{ }^{\circ} \mathrm{C}$.

\subsection{Model}

The modelled system is a stack of $n \varsigma: 1 \mathrm{Al} / \mathrm{CuO}$ bilayers. As evidenced on the Scanning Transmission Electron Microscopy (STEM) and Transmission Electron Microscopy (TEM) micrographs given in Supplementary file Figure S3, at ambient, both $\mathrm{CuO} / \mathrm{Al}$ and $\mathrm{Al} / \mathrm{CuO}$ interfaces are considered to have the same chemical nature (mixture of $\mathrm{Al}$, $\mathrm{Cu}, \mathrm{O})$ but different in thickness. The interface formed upon the deposition of $\mathrm{CuO}$ onto $\mathrm{Al}$ is of $4 \pm 0.3 \mathrm{~nm}$ in thickness whereas the interface created upon the deposition of $\mathrm{Al}$ onto $\mathrm{CuO}$ rough with an average thickness of $8 \pm 3 \mathrm{~nm}$. These barrier layers prevent the redox reaction from occurring at low temperatures $\left(<200{ }^{\circ} \mathrm{C}\right)$. Note that the redox reaction $2 \mathrm{Al}+3 \mathrm{CuO} \rightarrow \mathrm{Al}_{2} \mathrm{O}_{3}+3 \mathrm{Cu}$ is assumed with a heat of reaction $(Q)$ of $3.9 \mathrm{~kJ} / \mathrm{g}$ for stoichiometric conditions and $3.3 \mathrm{~kJ} / \mathrm{g}$ for a reactant $\mathrm{Al}: \mathrm{CuO}$ ratio of 2:1 as shown in [16]. 
Based on experimental observations described in previous section, a phenomenological model based on seven main mechanisms sketched in Figure 3, is implemented:

(1) Oxygen diffusion through the native interfaces. Activation energy $E_{a A_{x} C u_{y} O_{z}}$ and pre-exponent $D_{0} \mathrm{Al}_{x} \mathrm{Cu}_{y} \mathrm{O}_{z}$ are determined to fit the experimental first DSC peak (ם).

(2) Oxygen diffusion through $\mathrm{am}_{2} l_{2} \mathrm{O}_{3}$ characterized by activation energy and preexponent $\left(D_{0 \mathrm{am} \mathrm{Al}_{2} \mathrm{O}_{3}}, E_{a_{a m ~} l_{2} \mathrm{O}_{3}}\right)$.

(3) Oxygen release resulting from the $\mathrm{CuO}$ reduction in several steps. According to reference [17], the reduction of $\mathrm{CuO}$ thin films can be described by the progress function $f_{O}\left(\alpha_{O}\right)$ given by an Avrami-Erofeev mechanism:

$$
f_{O}\left(\alpha_{O}\right)=n \times\left(1-\alpha_{O}\right)\left[-\ln \left(1-\alpha_{O}\right)\right]^{(n-1) / n}
$$

The value of the reaction progress $\alpha_{O}$ is defined as being directly proportional to the global reaction progress $\alpha$ as follows: $\alpha_{O}=c_{O} \times \alpha . c_{0}$ is a coefficient adjusted to achieve the best match with the experimental DSC curves.

Thus, the oxygen release mechanism is expressed following equation 3 :

$$
\frac{d \alpha_{O}}{d t}=\mathrm{A}_{O} \exp \left(-E_{a_{O}} / R T\right) f_{O}\left(\alpha_{O}\right)
$$

The activation energy $\left(E_{a_{O}}\right)$ and pre-exponent $\left(\mathrm{A}_{O}\right)$ are fitted to DSC curves using the Kissinger method to obtain a first estimate, and then adjusted considering the progress function $f_{O}\left(\alpha_{O}\right)$.

(4) Oxygen diffusion through damaged $\mathrm{Al}_{2} \mathrm{O}_{3}$. We assume that the kinetic of $a m \mathrm{Al}_{2} \mathrm{O}_{3}$ to damaged $\mathrm{Al}_{2} \mathrm{O}_{3}$ transformation is directly linked to the oxygen release as follows:

$$
v_{\text {am } \rightarrow \text { damaged }}=v_{0} \frac{d \alpha_{O}}{d t}
$$


Where $v_{\text {am } \rightarrow \text { damaged }}$ is the growth velocity of damaged $\mathrm{Al}_{2} \mathrm{O}_{3}$ layer, and $v_{0}$ is a coefficient.

(5) Transformation of the $\mathrm{am}_{\mathrm{Al}} \mathrm{O}_{3}$ into a "porous $\gamma-\mathrm{Al}_{2} \mathrm{O}_{3}$ " according to the process described by Simpson et al. $[18,19]$. We assume that the kinetic of amorphous to porous $\gamma-\mathrm{Al}_{2} \mathrm{O}_{3}$ follows an Arrhenius law:

$$
v_{a m \rightarrow \gamma}=v_{0 a m \rightarrow \gamma} e^{-\frac{E_{a a m \rightarrow \gamma}}{R T}}
$$

where $v_{a m \rightarrow \gamma}$ is the growth velocity of porous $\gamma-\mathrm{Al}_{2} \mathrm{O}_{3}$ layer, $v_{0 a m \rightarrow \gamma}$ is the preexponent, and $E_{a a m \rightarrow \gamma}$ is the activation energy. Oxygen diffusion through porous alumina is considered very fast according to [20,21] but the oxygen diffusion resistance depends linearly on the oxide thickness as:

$$
D_{\text {porous }}=A_{\text {porous }}\left(1-\frac{w_{\text {porous }}}{w_{\text {porous }}^{\max }}\right) D_{\gamma-A l_{2} O_{3}}
$$

$D_{\text {porous }}$ and $D_{\gamma-A_{2} O_{3}}$ are the oxygen diffusion coefficients into the porous and bulk $\gamma-\mathrm{Al}_{2} \mathrm{O}_{3}$, respectively. $w_{\text {porous }}$ is the porous layer thickness and, $w_{\text {porous }}^{\max }$ is the thickness beyond which $D_{\text {porous }}=D_{\gamma-A l_{2} O_{3}} \cdot A_{\text {porous }}$ is a fitting coefficient corresponding to the initial value of oxygen diffusivity in the "porous $\gamma-\mathrm{Al}_{2} \mathrm{O}_{3}$ ". Once the porous layer diffusion resistance becomes higher than that of $\gamma-\mathrm{Al}_{2} \mathrm{O}_{3}$, the growth of amorphous $\mathrm{Al}_{2} \mathrm{O}_{3}$ is stopped and that of $\gamma-\mathrm{Al}_{2} \mathrm{O}_{3}$ is activated.

(6) Oxygen diffusion through $\gamma-\mathrm{Al}_{2} \mathrm{O}_{3}$ characterized by activation energy and preexponent $\left(\mathrm{D}_{0 \gamma-\mathrm{Al}_{2} \mathrm{O}_{3}}, E_{a_{\gamma-\mathrm{Al}_{2} \mathrm{O}_{3}}}\right)[21,22]$.

(7) Densification of $\mathrm{CuO}$. The sputter-deposited $\mathrm{CuO}$ density, $\rho_{0 \mathrm{CuO}}$, is most of the time less dense than bulk $\mathrm{CuO}$. Therefore, the $\mathrm{CuO}$ layer can shrink upon heating as observed experimentally in [6]. The densification is implemented as:

$$
v_{\text {CuO shrinkage }}=\left(\frac{w_{\text {CuO }}}{\rho_{\text {CuO }}}\right) \frac{d \rho_{\text {CuO }}}{d t}
$$


with $\frac{d \rho_{\text {CuO }}}{d t}=\left(\rho_{\text {th CuO }}-\rho_{0 \text { CuO }}\right) \frac{d \alpha_{\text {CuO shrinkage }}}{d t}$

$w_{C u O}$ and $\rho_{\text {Cuo }}$ are the $\mathrm{CuO}$ layer thickness and time-dependent density, respectively.

The progress rate of shrinkage $\frac{d \alpha_{C u O} \text { shrinkage }}{d t}$ is fitted to DSC curves using the Kissinger method assuming the determination of the activation energy $\left(E_{a_{\text {Cuo shrinkage }}}\right)$ and preexponent $\left(k_{0}\right.$ CuO shrinkage $)$ associated with this transformation reaction.

In addition, $\mathrm{Al}$ melting is considered in equation $7\left(\Delta H_{A l}^{m e l t}=10.79 \mathrm{~kJ} / \mathrm{mol}\right)$ whereas all phase transitions involving intermetallic compounds are neglected. Finally, to account for a spontaneous aluminum oxidation in the presence of oxygen, its reaction rate is fixed at high velocity, $3000 \mathrm{~m} / \mathrm{s}$, with no activation barrier [7].

Table 1 summarizes the activation energies and pre-exponents for each identified mechanism and their sources (DSC-based fitting, Kissinger or literature). In summary, the kinetic parameters describing mechanism 1, 3, 4, 5, and 7 are fitted from the DSC measurements (first ( $\bullet$ ) and second (•) peaks of Figure 2). Although reported to be fast, the diffusivity of oxygen in porous $\gamma-\mathrm{Al}_{2} \mathrm{O}_{3}$ layers (mechanism 5) is not documented in the literature. $D_{\text {porous } \gamma \mathrm{Al}_{2} \mathrm{O}_{3}}$, and growth velocity of porous layer, $v_{a m \rightarrow \gamma}$, were computed simultaneously in order to obtain the best match with the second DSC peak $(\bullet)$.

Because of the presence of huge number of defects, the diffusivity of oxygen in damaged $\mathrm{Al}_{2} \mathrm{O}_{3}$ (mechanism 4) should be even faster. As a consequence, and to avoid introducing arbitrary parameters into the model, oxygen diffusivity through this damaged $\mathrm{Al}_{2} \mathrm{O}_{3}$ layer is considered as infinite. In mathematical terms, the infinite diffusivity implies a uniform 
concentration of oxygen throughout the layer. Finally, the kinetic parameters describing, oxidative growth of am and $\gamma-\mathrm{Al}_{2} \mathrm{O}_{3}$ are taken from the literature [21,22].

Table 1. Model parameters for each mechanism.

\begin{tabular}{|c|c|c|}
\hline Mechanism & Parameters & Fitted to \\
\hline $\begin{array}{l}\text { Oxygen diffusion through } \\
\text { natural } \mathrm{Al}_{\mathrm{x}} \mathrm{Cu}_{\mathrm{y}} \mathrm{O}_{\mathrm{z}} \text {. }\end{array}$ & $\begin{array}{l}D_{0}{ }_{A l_{x} C u_{y} O_{z}}=1 \times 10^{-7} \mathrm{~m}^{2} / \mathrm{s} \\
E_{a_{A l_{x} C u_{y} O_{z}}}=100 \mathrm{~kJ} / \mathrm{mol}\end{array}$ & $\begin{array}{l}\text { DSC (peak a) } \\
\text { Figure } 2\end{array}$ \\
\hline $\begin{array}{l}\text { Oxygen diffusion through } \\
\mathrm{am} \mathrm{Al}_{2} \mathrm{O}_{3} \text {. }\end{array}$ & 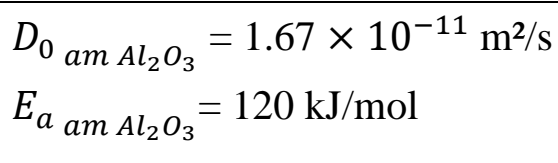 & [22] \\
\hline $\begin{array}{l}\text { Oxygen release from } \mathrm{CuO} \\
\text { reduction. }\end{array}$ & $\begin{array}{l}\mathrm{A}_{O}=1.3 \times 10^{4} \mathrm{~s}^{-1} \\
E_{a_{O}}=90 \mathrm{~kJ} / \mathrm{mol} \\
n=1.2 \\
c_{O}=0.18\end{array}$ & DSC (Figure 2 peak $\mathbf{\square})$ \\
\hline $\begin{array}{l}\text { Oxygen diffusion through } \\
\text { damaged } \mathrm{Al}_{2} \mathrm{O}_{3} \text {. }\end{array}$ & $\begin{array}{l}D_{\text {damaged } \gamma_{\mathrm{Al}_{2} \mathrm{O}_{3}}=\infty} \\
v_{0}=3 \times 10^{-8}\end{array}$ & DSC (Figure 2 peak $\boldsymbol{\square})$ \\
\hline $\begin{array}{l}\text { Amorphous } \rightarrow \gamma \\
\text { polymorphic phase } \\
\text { transformation in } \mathrm{Al}_{2} \mathrm{O}_{3} \text {. }\end{array}$ & $\begin{array}{l}v_{0 a m \rightarrow \gamma}=1.5 \times 10^{7} \mathrm{~m} / \mathrm{s} \\
E_{a} a m \rightarrow \gamma\end{array}$ & $\begin{array}{l}\text { Kissinger methods } \\
\text { Figure } \mathbf{S 2}\end{array}$ \\
\hline $\begin{array}{l}\text { Oxygen diffusion through } \\
\text { porous } \gamma-\mathrm{Al}_{2} \mathrm{O}_{3} \text {. }\end{array}$ & $\begin{array}{l}w_{\text {porous }}^{\max }=21 \mathrm{~nm} \\
A_{\text {porous }}=700\end{array}$ & DSC (Figure 2 peak $\bullet$ ) \\
\hline $\begin{array}{l}\text { Oxygen diffusion through } \\
\gamma-\mathrm{Al}_{2} \mathrm{O}_{3} \text {. }\end{array}$ & $\begin{array}{l}D_{0 \gamma-A l_{2} O_{3}}=5 \times 10^{-5} \mathrm{~m}^{2} / \mathrm{s} \\
E_{a_{\gamma-A l_{2} O_{3}}}=290 \mathrm{~kJ} / \mathrm{mol}\end{array}$ & {$[21,22]$} \\
\hline $\mathrm{CuO}$ densification. & $\begin{array}{l}k_{0} \text { Cuo shrinkage } \\
=3 \times 10^{-10} \mathrm{~s}^{-1} \\
E_{a_{\text {CuO shrinkage }}}=177 \mathrm{~kJ} / \mathrm{mol}\end{array}$ & DSC (Figure 2 peak $\boldsymbol{\square})$ \\
\hline
\end{tabular}

The reaction model with the adjusted kinetic parameters is finally implemented into numerical codes in $\mathrm{C}$ to predict the evolution of the different layer thicknesses $(\mathrm{Al}, \mathrm{CuO}$, $\mathrm{Cu}_{2} \mathrm{O}, \mathrm{Al}_{2} \mathrm{O}_{3} \ldots$ ), upon annealing, and to simulate virtual DSC of sputter-deposited $\mathrm{Al} / \mathrm{CuO}$ multilayers (see Supplementary file Figure S5). Comparison between calculated and experimental results are presented and discussed in the next subsection before presenting the effect of thermal annealing on thermal response. 


\subsection{Model vs experiments comparison}

Alumina growth simulation upon heating. Figure 4 plots the thickness evolution of the growing $\mathrm{Al}_{2} \mathrm{O}_{3}$ barrier layer at both interfaces when increasing the temperature of a trilayer $\mathrm{Al} / \mathrm{CuO} / \mathrm{Al}$ with $\mathrm{Al}$ and $\mathrm{CuO}$ thicknesses equal to 100 and $300 \mathrm{~nm}$, respectively. The ramping is $10{ }^{\circ} \mathrm{C} \cdot \mathrm{min}^{-1}$ and a 10 minutes annealing step is performed at selected temperatures, $25,200,300,350,400,500{ }^{\circ} \mathrm{C}$, after which high magnification TEM images are taken allowing determination of oxide layer thicknesses (summarized in Supplementary file Figure S3).

Dashed lines correspond to simulations of the overall annealing procedure and small triangles and circles give the experimental measurements. Overall, simulations match well with experimental data : 25\% discrepancy is obtained due to noticeable deviation at high temperatures $\left(500{ }^{\circ} \mathrm{C}\right)$, which is reasonable since mechanisms such as delamination or potential $\mathrm{Al} / \mathrm{Cu}$ allowing evidenced experimentally [6] are not taken into account in the model.

At low temperature (below $200{ }^{\circ} \mathrm{C}$ ), the simulated amorphous alumina growth rates look similar despite the pre-existence of differences in natural interface thicknesses. However, the much higher roughness of the $\mathrm{CuO} / \mathrm{Al}$ interface leads to poor precision of the measured thickness, as seen from the error bars, which hinders quantitative comparison. The underestimation of simulated thicknesses at $200{ }^{\circ} \mathrm{C}$ may arise from the cooling down of the experimental which is not spontaneous and may promote further oxide growth. In the intermediate regime, $\sim 300-350{ }^{\circ} \mathrm{C}$, the alumina growth rate suddenly increases at both interfaces. We assume that the growing amorphous alumina becomes permeable to oxygen migration due a stress-induced deterioration of the layer. This causes a brutal enhancement of the redox reaction and oxidation rate $(\times 5)$. 
Interestingly, in this transition, we observe a crossing over of experimental and simulated curves, leading to overestimation of the grown thicknesses at $500{ }^{\circ} \mathrm{C}$, for both interfaces. This effect can be related to the fact that parameters of influence here emanate from DSC measurements in which we assume complete overall exothermic $\mathrm{Al}+\mathrm{O}$ reactions, which is never the case experimentally.

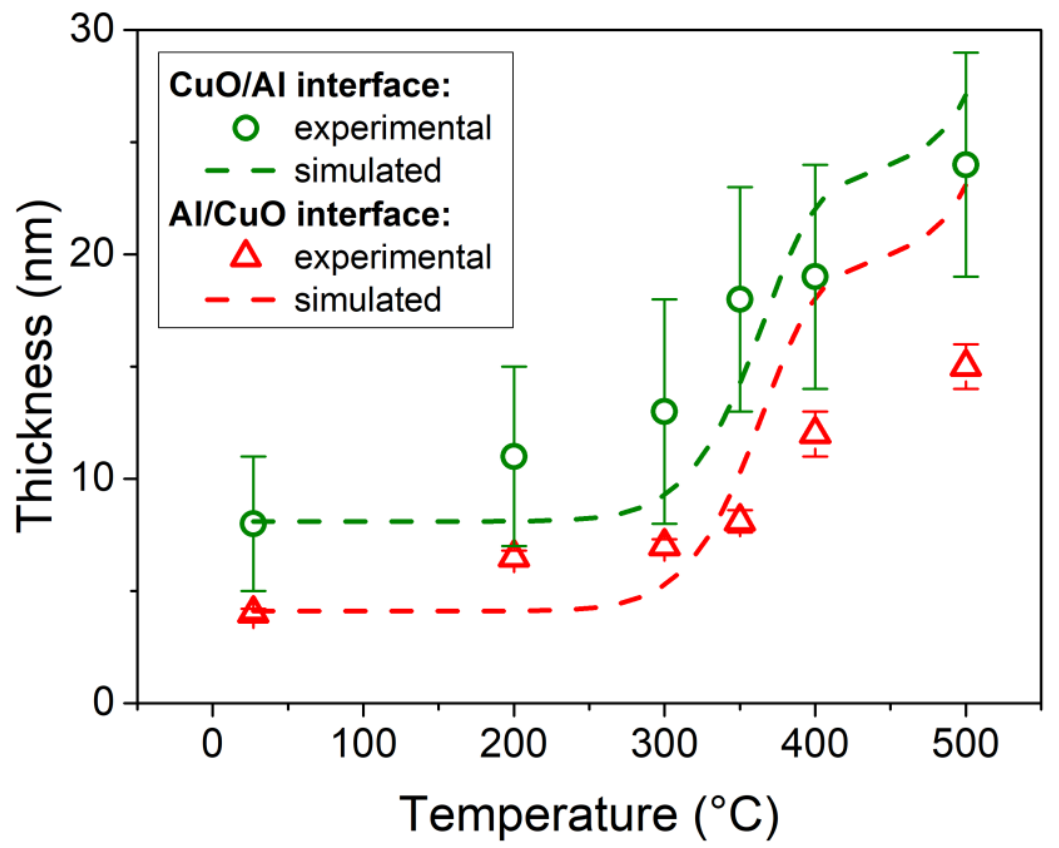

Figure 4. Simulated and measured interfacial oxide layers thickness evolution upon heating. Heating rate is $10{ }^{\circ} \mathrm{C} \cdot \mathrm{min}^{-1}$ and $\mathrm{Al} / \mathrm{CuO} / \mathrm{Al}$ stacks (total thickness of $500 \mathrm{~nm}$ ) are annealed $10 \mathrm{~min}$ at each selected temperature $\left(25,200,300,350,400,500{ }^{\circ} \mathrm{C}\right)$. Calorimetric response simulation. Figure 5 compares the thermo-analysis experiments (dashed line) with simulated one (solid line) obtained with a ramping of $10{ }^{\circ} \mathrm{C} \cdot \mathrm{min}^{-1}$ for two samples of $\mathrm{Al} / \mathrm{CuO}$ multilayers made of ten bilayers $(w=300 \mathrm{~nm}$ and $600 \mathrm{~nm}$ ) prepared in stoichiometric condition $(\varsigma=1)$. Note that the choice of ten $1: 1 \mathrm{Al} / \mathrm{CuO}$ bilayers is made to avoid working on the same type of sample that were used to parameterize the model. 


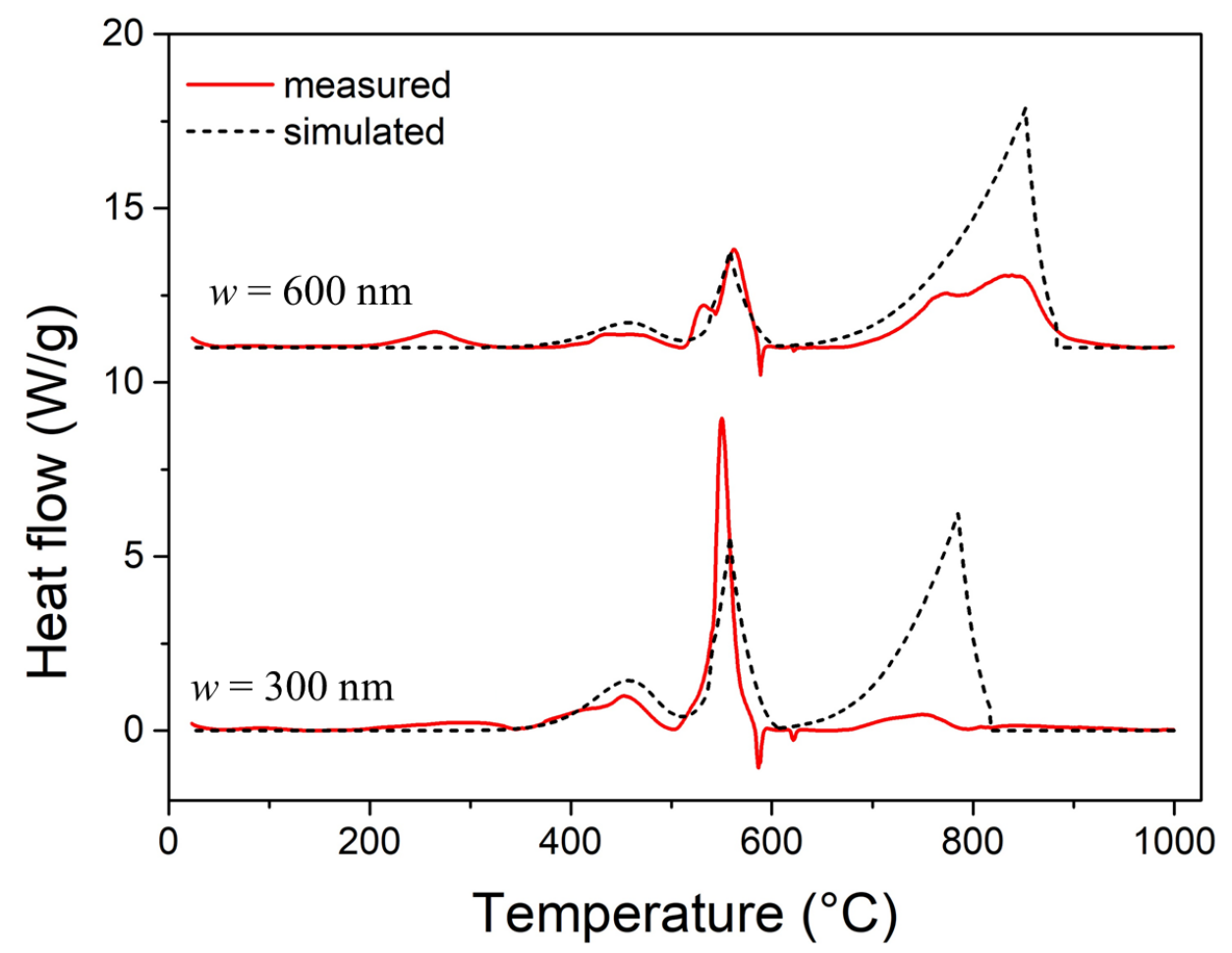

Figure 5. Simulated (dashed lines) and experimental (solid lines) DSC traces for ten 1:1 $\mathrm{Al} / \mathrm{CuO}$ bilayers featuring two bilayer thicknesses: 600 and $300 \mathrm{~nm}$.

The model simulates all exotherms obtained in experimental DSC: it predicts the three main reaction steps at $440,578{ }^{\circ} \mathrm{C}$ and close to $800{ }^{\circ} \mathrm{C}$ with very good accuracy. Further, in the absence of any accurate data, the theoretical melting of $\mathrm{Al}$ has been set to $660{ }^{\circ} \mathrm{C}$ (endotherm) the bulk melting point, whereas it experimentally occurs at a lower temperature, due to the nanometric thickness of the layer. However, no exotherm is predicted below $300{ }^{\circ} \mathrm{C}$ whereas we can detect weak exotherms experimentally at around $250{ }^{\circ} \mathrm{C}$ (especially for thicker bilayer $w=600 \mathrm{~nm}$ ), which may be due to dehydration or recrystallization.

\subsection{Aging prediction}

The model is now used to predict how long-term thermal annealing affects multilayers thermal properties. For that purpose, we now consider 3 samples of ten $2: 1 \mathrm{Al} / \mathrm{CuO}$ 
bilayers, each layer being $200 \mathrm{~nm}$ thick ( $w=400 \mathrm{~nm}$ ), as commonly used for ignition applications.[23,24] One of these samples is characterized by DSC after deposition [6], the two others are annealed two weeks at $100{ }^{\circ} \mathrm{C}$ and $200{ }^{\circ} \mathrm{C}$ respectively, before being characterized by DSC.

In parallel, we simulated the growing alumina thickness at the interface during the annealing steps (See Figure 6) at 100 and $200{ }^{\circ} \mathrm{C}$.

At $100{ }^{\circ} \mathrm{C}$, no noticeable modification of interface thicknesses is observed; the overall reaction progress remains below $0.04 \%$ of the initial heat of reaction after two weeks, and it reaches $1.6 \%$ after one year. At $200{ }^{\circ} \mathrm{C}$, the reaction progress reaches $14.9 \%$ of the initial heat of reaction after two weeks, and increases only to $16.8 \%$ after one year. We predict a slight increase of the interface thickness corresponding to the growth of an ultrathin layer of amorphous alumina: the $\mathrm{am}_{\mathrm{Al}} \mathrm{l}_{2} \mathrm{O}_{3}$ growth is $0.25 \mathrm{~nm}$ and $2.6 \mathrm{~nm}$ after two weeks and one year annealing at $100{ }^{\circ} \mathrm{C}$, respectively. At $200{ }^{\circ} \mathrm{C}$ the $a m \mathrm{Al}_{2} \mathrm{O}_{3}$ growth is $22.6 \mathrm{~nm}$ and $19.4 \mathrm{~nm}$ after two weeks and one year, respectively. The discontinuous behaviour observed on top left graph in Figure 6 corresponds to the quick formation of a diffusion barrier when the temperature is brutally switched from ambient to higher temperatures.
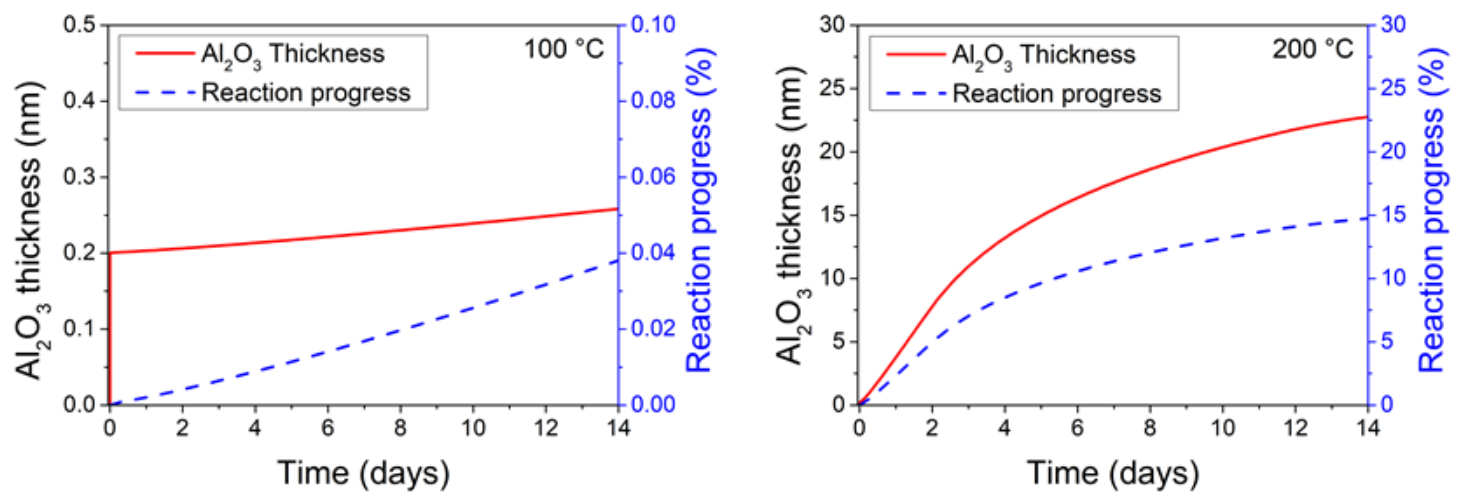

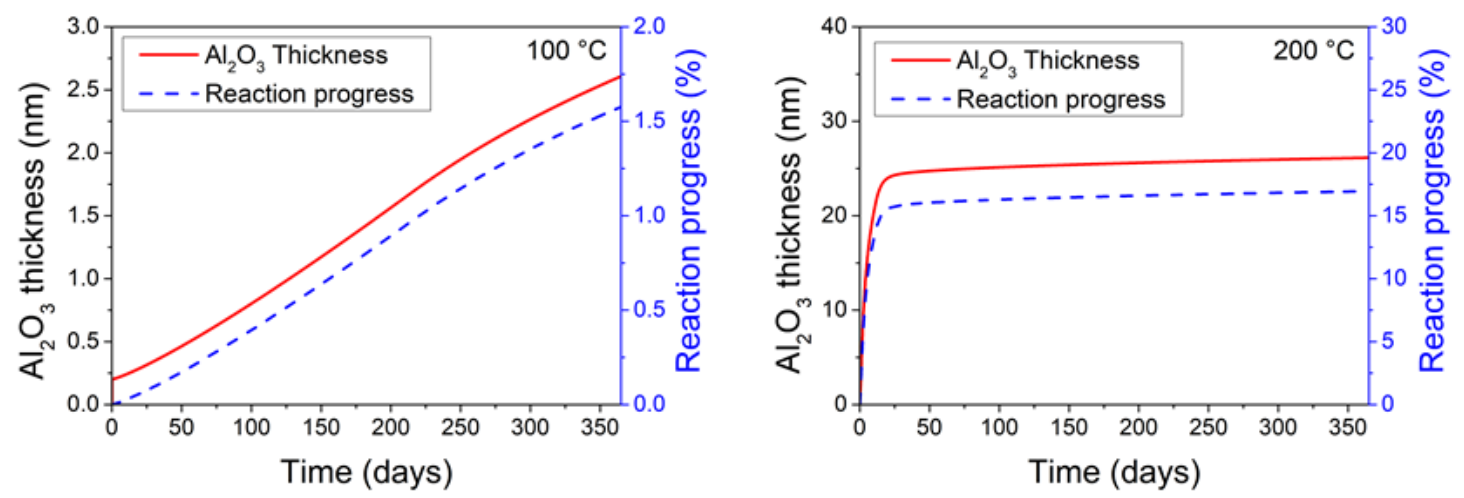

Figure 6. Simulated $\mathrm{am}_{\mathrm{Al}} \mathrm{O}_{3}$ growth and reaction progress (dashed line) for ten 2:1

$\mathrm{Al} / \mathrm{CuO}$ bilayers $(w=400 \mathrm{~nm})$ annealed two weeks and one year at 100 and $200{ }^{\circ} \mathrm{C}$.

DSC traces of aged samples are plotted in Figure 7 with simulated ones. We observe consistent results with the evolution of oxide layer thickness plotted in Figure 6. Even though all mechanisms are considered to be active at all steps of the reaction, we already saw that DSC is typically characterized by a first exotherm ( at $440{ }^{\circ} \mathrm{C}$ in Figure 5) corresponding the first step of copper oxide reduction releasing oxygen atoms that diffuse across the natural interfacial layer to oxidize the neighboring aluminum and form amorphous alumina ( $\mathrm{am}_{\mathrm{Al}} \mathrm{O}_{3}$ ). The model indicates us that annealing the bilayer 10 days at $200{ }^{\circ} \mathrm{C}$, is enough to grow a thin $20 \mathrm{~nm} \mathrm{am} \mathrm{Al}_{2} \mathrm{O}_{3}$ thus modifying the nature of the interfaces. As a result, the first exotherm usually seen on as deposited films disappears from the DSC scan after the annealing procedure (See Figure 7). The second exotherm is associated with the transformation of amorphous alumina into a $\gamma-\mathrm{Al}_{2} \mathrm{O}_{3}$. We observe that the intensity of the second exotherm remains unchanged for samples annealed at 100 ${ }^{\circ} \mathrm{C}$ and $200{ }^{\circ} \mathrm{C}$ in comparison with the freshly produced samples.

These results are valuable because they not only provide information about the reaction progress, but also on which mechanisms are affected during the aging process. The vanishing of low temperatures exotherms may have a strong impact on combustion 
behaviour, such as higher ignition time or lower flame velocity. After observing the endotherm of aluminum melting at $660{ }^{\circ} \mathrm{C}$, a third exotherm peak is seen, which is related to the activation of the oxygen diffusion trough $\gamma$-alumina. A good qualitative agreement is observed between the experimental and calculated peaks over both annealing. The slight overestimation may be due to lacking high temperature phenomena in the model that affect DSC experimental measurements, such as delamination of $\mathrm{Al} / \mathrm{CuO}$ interfaces.

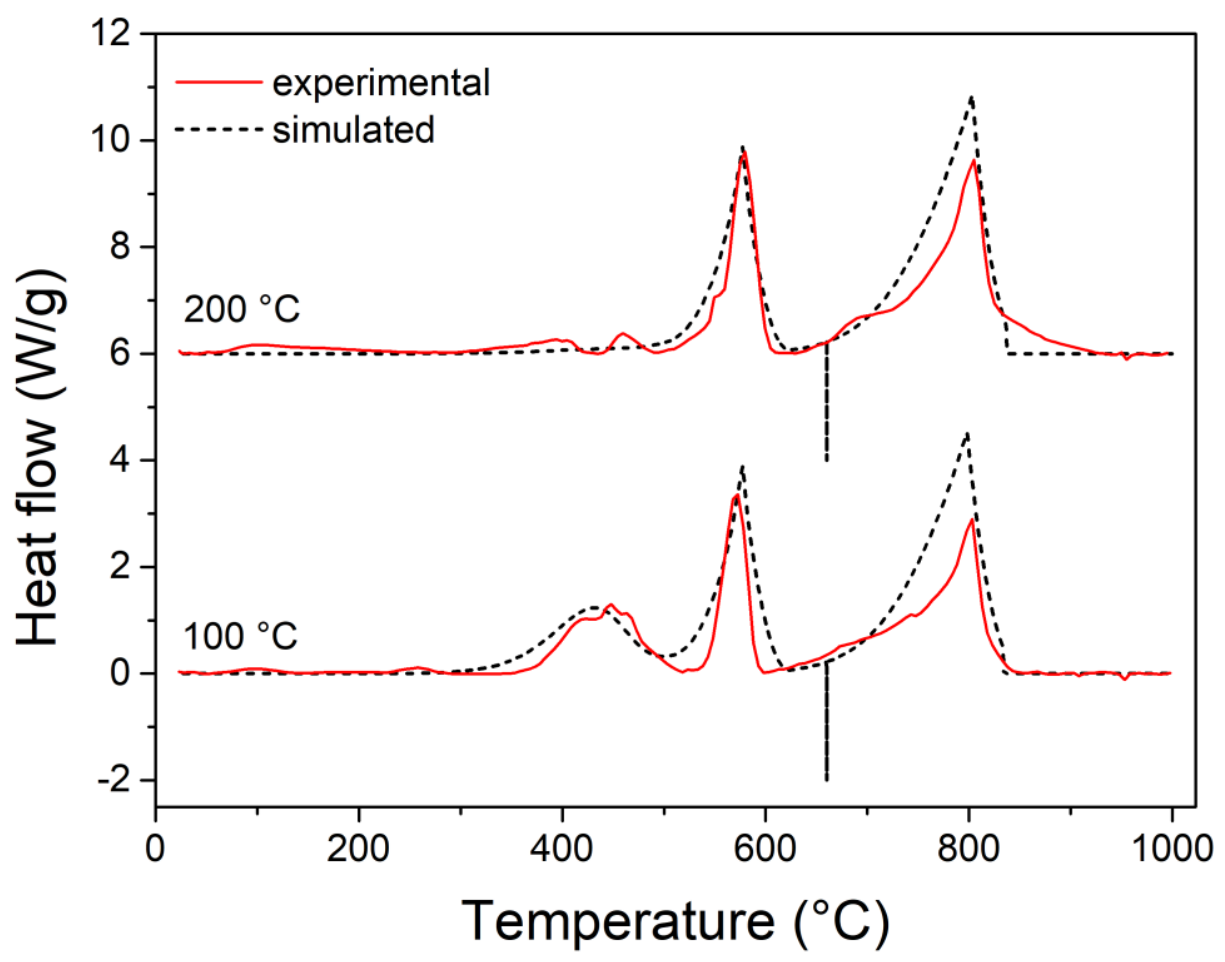

Figure 7. Simulated and experimental DSC traces of samples made of ten 2:1 Al/CuO bilayers $(w=400 \mathrm{~nm})$ annealed two weeks at 100 and $200{ }^{\circ} \mathrm{C}$.

\subsection{Influence of the ramping}

In the following, we consider ten 2:1 Al/CuO bilayers, each layer being $200 \mathrm{~nm}$ thick $(w=400 \mathrm{~nm})$ and simulated their calorimetric responses at different ramping : 100, 1000 and $10^{9}{ }^{\circ} \mathrm{C} \cdot \mathrm{min}^{-1}$ (See Figure 8). 
Increasing the ramping temperature to $100{ }^{\circ} \mathrm{C} \cdot \mathrm{min}^{-1}$, we only observe two main exotherms, where three were visible at $10{ }^{\circ} \mathrm{C} \cdot \mathrm{min}^{-1}$. This is due to the merging process of the first two exotherms, which process is clearly visible from the associated DSC curve in Figure 8, with a shouldering of the first peak. Increasing heating rate to $10^{9}{ }^{\circ} \mathrm{C} \cdot \mathrm{min}^{-1}$ does not modify the thermal response. Except for the preceding merging process that is no more distinguishable for both 1000 and $10^{9}{ }^{\circ} \mathrm{C} \cdot \mathrm{min}^{-1}$ ramps. Interestingly, the overall exotherm temperature onset has shifted from 400 to roughly $1000{ }^{\circ} \mathrm{C}$ which could be correlated to the various initiation temperatures required by different ignition apparatus: hot wire, laser, resistor ... In this scope, this phenomenological model could easily be turned to simulate initiation and propagation of a realistic multilayer, as in [7]. This would allow, within a single physico-chemical core calculation, (i) to predict $\mathrm{Al} / \mathrm{CuO}$ multilayers aging, (ii) to perform virtual DSC characterization and (iii) to determine associated performances.
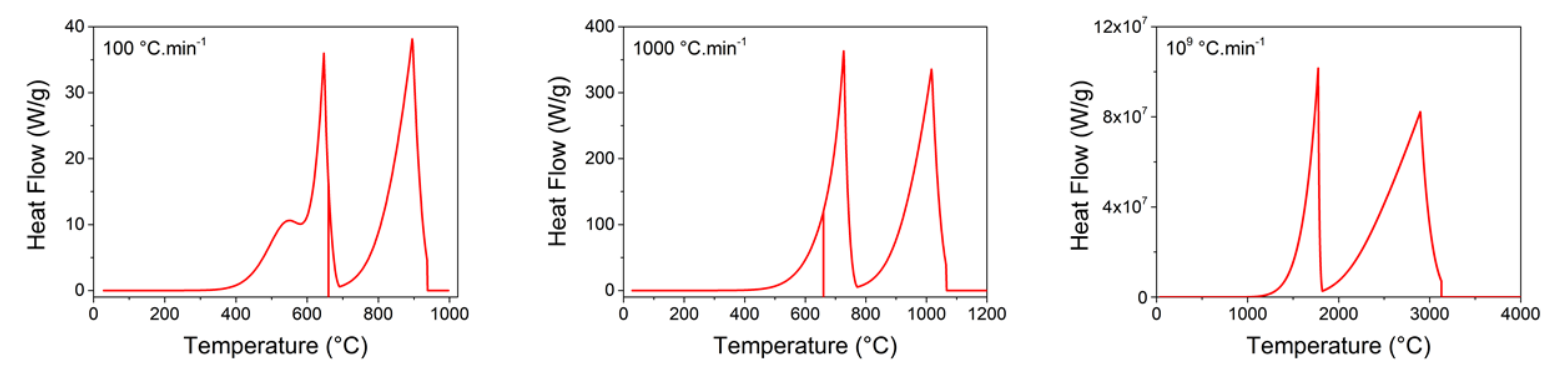

Figure 8. Simulated DSC curves for ten $2: 1 \mathrm{Al} / \mathrm{CuO}$ bilayer $(w=400 \mathrm{~nm})$ at three different heating rates, 100,1000 and $10^{9}{ }^{\circ} \mathrm{C} \cdot \mathrm{min}^{-1}$.

\section{Conclusion}

A heterogeneous redox reaction model was developed integrating an ensemble of basic mechanisms (oxygen diffusion, structural transformations, polymorphic phase changes) that have been collected from experimental investigations. The reaction model assumes that the rate of reaction is limited by transport of oxygen across the growing layer of 
$\mathrm{Al}_{2} \mathrm{O}_{3}$ separating $\mathrm{Al}$ and $\mathrm{CuO}$. For each mechanism, kinetic parameters are adjusted based on results taken from the literature or to fit with one set of experimental DSC obtained on 2:1 $\mathrm{Al} / \mathrm{CuO}$ multilayers. The model was used to simulate the calorimetric response of $\mathrm{Al} / \mathrm{CuO}$ multilayers, with different reactant ratios (different from validation set) and thicknesses, performed isothermally at well-controlled heating rates. The simulated results qualitatively match the experimental observations. We further demonstrated that this new theoretical tool can easily predict how temperature ramp affects the structure of the multilayer and especially the growth of interface $\left(\mathrm{Al}_{2} \mathrm{O}_{3}\right)$ making it possible, for the first time, to evaluate individual to synergistic exothermic reaction steps which dominate the different stages of reaction progress. As a perspective, this model could further simulate ignition involving much higher heating rates than thermo-analytical technique and therefore constitute a precious tool to design energetic multilayered systems requiring reliable prediction of their ignition kinetics, energetics and, aging.

Acknowledgements, avoiding identifying any of the authors prior to peer review

\section{Acknowledgements}

This research was supported by the CEA-DIF, CNRS and IDEX grant MUSE from the Université Fédérale de Toulouse. This work was made possible through the support of the European Commission and Region Occitanie for their FEDER support (THERMIE grant) having funded the sputter deposition equipment and differential scanning calorimeter. We also thank CALMIP supercomputer center for computing resources. We thank as well Teresa Hungria-Hernandez and Claudie Josse from "Centre de Micro Caractérisation Raymond Castaing (UMS 3623)" for their great support with STEM experiments. We also thank Claude Marcandella from CEA-DIF for their support in thermal aging studies.

\section{References}


[1] G. Taton, D. Lagrange, V. Conedera, L. Renaud and C. Rossi, Micro-chip initiator realized by integrating $\mathrm{Al} / \mathrm{CuO}$ multilayer nanothermite on polymeric membrane, J. Micromechanics Microengineering 23 (2013), pp. 105009.

[2] J.Y. Ahn, S.B. Kim, J.H. Kim, N.S. Jang, D.H. Kim, H.W. Lee et al., A micro-chip initiator with controlled combustion reactivity realized by integrating $\mathrm{Al} / \mathrm{CuO}$ nanothermite composites on a microhotplate platform, J. Micromechanics Microengineering 26 (2016), pp. 015002.

[3] P. Zhu, R. Shen, Y. Ye, S. Fu and D. Li, Characterization of $\mathrm{Al} / \mathrm{CuO}$ nanoenergetic multilayer films integrated with semiconductor bridge for initiator applications, J. Appl. Phys. 113 (2013), pp. 184505.

[4] N.A. Manesh, S. Basu and R. Kumar, Experimental flame speed in multi-layered nano-energetic materials, Combust. Flame 157 (2010), pp. 476-480.

[5] J. Kwon, J.M. Ducéré, P. Alphonse, M. Bahrami, M. Petrantoni, J.-F. Veyan et al., Interfacial Chemistry in Al/CuO Reactive Nanomaterial and Its Role in Exothermic Reaction, ACS Appl. Mater. Interfaces 5 (2013), pp. 605-613.

[6] I. Abdallah, J. Zapata, G. Lahiner, B. Warot-Fonrose, J. Cure, Y. Chabal et al., Structure and Chemical Characterization at the Atomic Level of Reactions in Al/CuO Multilayers, ACS Appl. Energy Mater. (2018), .

[7] L. Marin, C.E. Nanayakkara, J.-F. Veyan, B. Warot-Fonrose, S. Joulie, A. Esteve et al., Enhancing the Reactivity of $\mathrm{Al} / \mathrm{CuO}$ Nanolaminates by $\mathrm{Cu}$ Incorporation at the Interfaces, Acs Appl. Mater. Interfaces 7 (2015), pp. 11713-11718.

[8] S.M. Umbrajkar, M. Schoenitz and E.L. Dreizin, Exothermic reactions in $\mathrm{Al}-\mathrm{CuO}$ nanocomposites, Thermochim. Acta 451 (2006), pp. 34-43.

[9] H. E. Kissinger, Reaction Kinetics in Differential Thermal Analysis, Anal Chem 29 (1957), pp. 1702-1706.

[10] K.J. Blobaum, A.J. Wagner, J.M. Plitzko, D. Van Heerden, D.H. Fairbrother and T.P. Weihs, Investigating the reaction path and growth kinetics in $\mathrm{CuOx} / \mathrm{Al}$ multilayer foils, J. Appl. Phys. 94 (2003), pp. 2923.

[11] M. Fathollahi, S.M. Pourmortazavi and S.G. Hosseini, Particle Size Effects on Thermal Decomposition of Energetic Material, J. Energ. Mater. 26 (2007), pp. 5269.

[12] P.E. Sánchez-Jiménez, J.M. Criado and L.A. Pérez-Maqueda, Kissinger kinetic analysis of data obtained under different heating schedules, J. Therm. Anal. Calorim. 94 (2008), pp. 427-432.

[13] A. Khawam and D.R. Flanagan, Solid-State Kinetic Models: Basics and Mathematical Fundamentals, J. Phys. Chem. B 110 (2006), pp. 17315-17328.

[14] B.E. Deal and A.S. Grove, General Relationship for the Thermal Oxidation of Silicon, J. Appl. Phys. 36 (1965), pp. 3770-3778.

[15] G. Lahiner, A. Nicollet, J. Zapata, L. Marín, N. Richard, M.D. Rouhani et al., A diffusion-reaction scheme for modeling ignition and self-propagating reactions in Al/CuO multilayered thin films, J. Appl. Phys. 122 (2017), pp. 155105.

[16] Multilayered $\mathrm{Al} / \mathrm{CuO}$ thermite formation by reactive magnetron sputtering: Nano versus micro, J. Appl. Phys. 108 (2010), pp. 084323.

[17] J. Li, J. Mayer and K. Tu, Nucleation and growth of $\mathrm{Cu} 2 \mathrm{O}$ in the reduction of $\mathrm{CuO}$ thin films, Phys. Rev. B Condens. Matter 45 (1992), pp. 5683-5686.

[18] M.A. Trunov, M. Schoenitz and E.L. Dreizin, Effect of polymorphic phase transformations in alumina layer on ignition of aluminium particles, Combust. Theory Model. 10 (2006), pp. 603-623. 
[19] T.W. Simpson, Q. Wen, N. Yu and D.R. Clarke, Kinetics of the Amorphous $\rightarrow \gamma \rightarrow \alpha$ Transformations in Aluminum Oxide: Effect of Crystallographic Orientation, J. Am. Ceram. Soc. 81 (1998), pp. 61-66.

[20] M.A. Trunov, M. Schoenitz and E.L. Dreizin, Ignition of Aluminum Powders Under Different Experimental Conditions, Propellants Explos. Pyrotech. 30 (2005), pp. 36-43.

[21] D. Stamatis, A. Ermoline and E.L. Dreizin, A multi-step reaction model for ignition of fully-dense Al-CuO nanocomposite powders, Combust. THEORY Model. 16 (2012), pp. 1011-1028.

[22] Toshihide Nabatame, Tetsuji Yasuda, Masayasu Nishizawa, Minoru Ikeda, Tsuyoshi Horikawa and Akira Toriumi, Comparative Studies on Oxygen Diffusion Coefficients for Amorphous and $\gamma$-Al2O3 Films using $18 O$ Isotope, Jpn. J. Appl. Phys. 42 (2003), pp. 7205.

[23] A. Nicollet, G. Lahiner, A. Belisario, S. Souleille, M. Djafari-Rouhani, A. Esteve et al., Investigation of $\mathrm{Al} / \mathrm{CuO}$ multilayered thermite ignition, J. Appl. Phys. 121 (2017), pp. 034503.

[24] A. Nicollet, L. Salvagnac, V. Baijot, A. Estève and C. Rossi, Fast circuit breaker based on integration of Al/CuO nanothermites, Sens. Actuators Phys. (2018), . 